\title{
Innovative models for sustainable agriculture
}

\author{
Stefan Ghimisi ${ }^{1}$ \\ ${ }^{1}$ Constantin Brancusi University of Targu Jiu, Romania \\ E-mail:ssghimisi@gmail.com
}

\begin{abstract}
In the full global crisis, innovation must play an active part in solving problems facing the countries of the world. Investing in research and development and production of innovations is a practical and efficient way to combat recession. The paper presents some innovation models used for the development of a sustainable agriculture, the choice of the optimal innovation model can lead to the development of society
\end{abstract}

Keywords: innovation, agriculture, sustainable

\section{Definitions and evolutions}

In 1941, English economist Schumpeter [1] proposed the first definition, in technical-economical domain, innovation, definition with general character. He says that innovation is the action whose outcome is to produce anything or to produce otherwise. As Schumpeter's definition, it is recognized that the innovation in the following activities: a new product creation introduction of new manufacturing methods; entering a new market (creating a new market); appealing to a new material; new organization of the company; create a new image of the company.

The classic definitions of "innovation" include:

- "the process of making improvements by introducing something new".

- "the act of introducing something new: something newly introduced". (The American Heritage Dictionary of the English Language)

- "the introduction of something new". (Merriam-Webster Online)

- "a new idea, method or device". (Merriam-Webster Online)

- "the successful exploitation of new ideas". (Department of Trade and Industry,UK)

- "change that creates a new dimension of performance". Peter Drucker (Hesselbein, 2002)

- "a creative idea that is realized". Frans Johansson (Harvard Business School Press, 2004)

\section{Innovation Models}

Many innovations result from seeking a new opportunity. Potential innovator must know that there are principles of innovation. These principles can be improved and allow people to innovate.

Thus:

1. Be oriented towards action, innovators always seek new ideas, new opportunities and new sources of innovation.

2. To make the product, process or service innovation, to be simple and understandable.

3. People have to easily understood how innovation function

4. To achieve product, process, service based on customer preferences.

5. To start with small-scale innovation. 
6. Need for targeted high objectives. Successful innovators should aim at trying to find a niche market for innovative product.

7. Innovators must follow the rule: attempt, test, review.

8. Learn from mistakes. Innovation does not guarantee success. Analysis of fault may give rise to another innovation.

9. Need to develop a schedule of the innovative project with periodic inspections.

10. Need to be rewarded those involved heavily in innovation activity.

\section{1 "Technology push" model}

The "Technology push" model is a linear model suggests that the innovation process starts with an idea. Sometimes the process has the idea / invention only a single man who has knowledge and skills that would transform the idea / invention into innovation. Nowadays the starting point of the innovation process is the process of research and development in the enterprise. This process includes product design and development can be put into production with minimal costs and can be done at a good price.

Thus the market is seen as a receiver of the proposed products from research and development process. Therefore an increase in research and development leads to increased innovation. In the past governments support innovation in many countries, this process was to support research and development through direct financing. A team of research and development implies that knows enough about the consumer needs to develop a new product without consumer participation.

Technology push model of innovation has not successful in all cases because sometimes the proposed innovations are not sufficiently appreciated by the customer and the product does not ensure expectations.

\section{2. "Market pull" model}

Alternatively, the "market pull "model suggests that the need for innovation comes from consumers or market segment. These needs may be perceived by entrepreneurs or producers or consumers are clearly manifested. According to this model for a subsequent successful innovation is necessary first to investigate market needs, establishing the needs of both existing products and processes and how to meet the needs of new innovative product.

Therefore this model adds "Technology push "model research phase of market needs (figure 1).

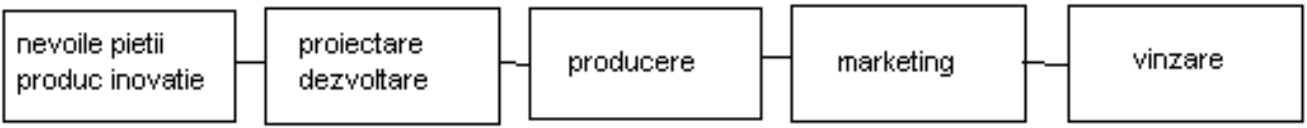

Figure 1.Market pull model

\subsection{Model of innovation chain-link}

It is a third generation model of innovation third and is proposed by SJ Kline, N. Rosenberg [2]. Following this model the innovation process is divided into five stages. In the first stage it is identified the consumers needs on a potential market. The second stage begins with an invention or / analytical project with the new product or process which as planned will meet the needs found. In the third stage takes place design and testing, and innovation process itself. In the fourth stage the project is growing and is introduced in series production. Fifth stage of innovation is to present the innovation on the market with the marketing process and distribution beginning .

Characteristic of this model is the presence of five relations of the innovation process, describing the different origins of innovation and knowledge to enter, related to the innovation process( figure 2). Main link with the index denoted by arrow $\mathrm{C}$ (Central Chain) make a process generalization which occur as a response to market needs, invention or analytical design, development and production to the marketing process.

The second link of the innovation process reflects feedback during the duration of the main link. 
The most important part of feedback, represented by F (feedback), comes from the consumer or user of the future customer of the innovation. This link reminds us that innovation is the source of consumer, or that they are consumer-oriented innovation processes. The second link shows the occurred feedback in the enterprise, noted f (feedback), and presents the company work to solve / skip issues that may arise at different stages of innovation, or the source innovation which is to learn from the experience (learning by doing).

The third link in the main link connecting the innovation process with knowledge. This link between innovation and fundamental research is denoted by D (discoveries), so for example many innovations are directly related to scientific research process appearing like enterprise and universities cooperation.

The fourth link in the process of innovation denoted by $\mathrm{K}$ (knowledge) as the first source innovation evidences the existing knowledge and in the second place the new emerging knowledge if the existing knowledge can not meet needs.

The fifth link, denoted by I (Innovation) reflects the possibilities open by the innovation for scientific progress. This means the utilization of innovations to make scientific research that will give new inventions.

\section{Chain-linked model}

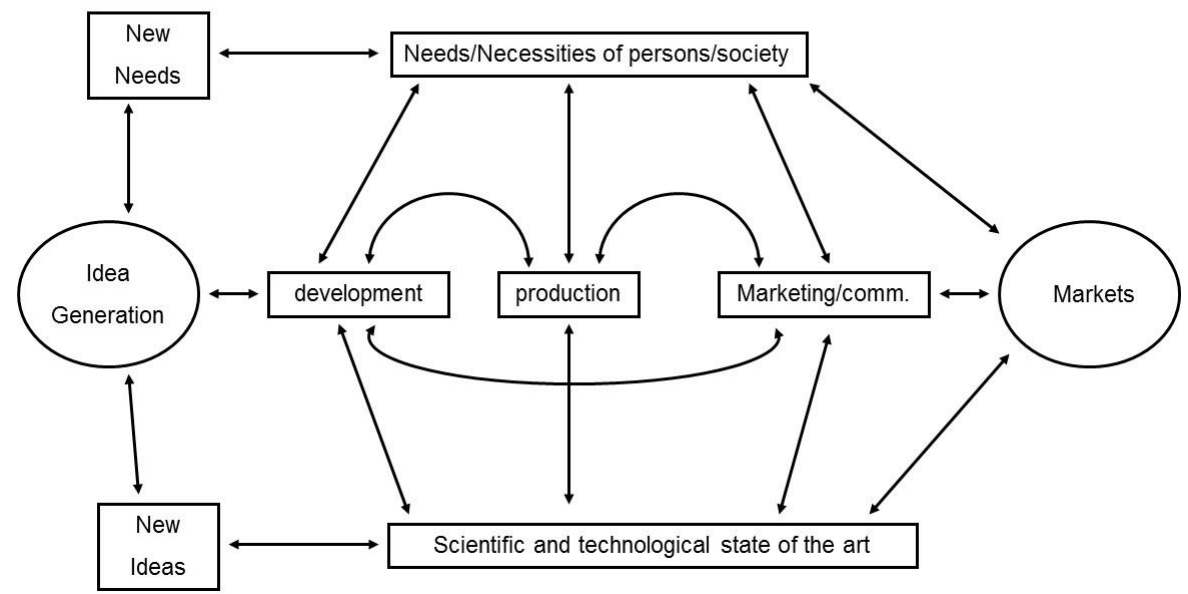

Figure 2. Model of innovation chain-

\subsection{The triple helix model}

The "triple helix" is a spiral model of innovation that captures multiple reciprocal relationships at different points in the process of knowledge capitalization. The first dimension of the triple helix model is internal transformation in each of the helices, such as the development of lateral ties among companies through strategic alliances or an assumption of an economic development mission by universities. The "triple helix" of university-agrculture-government relations is a neo-evolutionary model of innovation process is a model for analyzing innovation in the economy based on knowledge.

Definition given by Henry Etzkowitz (2002) [3] mentions that "triple helix is a spiral type innovation model which describes the mutual relations in many different points of the accumulation of knowledge process." This concept has been approached by some Romanian authors, such as Miron, D. (2008) [4] N. F.G.Filip and Vasiliu (2009) [5].VINNOVA Swedish Agency for Innovation adopted triple helix model in order to provide efficient solutions to the problems of generation, technology transfer and use of new knowledge. The triple helix denotes the university-agriculture-government relationship as one of relatively equal, yet interdependent, institutional spheres which overlap and take the role of the other. There has been a movement from separate institutional spheres, which represent, at least in ideology, the US situation. There has also been a shift from the model of the state encompassing agriculture and 
academia, in its strongest form in the former Soviet Union but versions could also be found in Latin American and European countries.

Bilateral relations between government and university, academia and agriculture and government and agriculture have expanded into triadic relationships among the spheres, especially at the regional level. Academic-agriculture-government relations are emerging from different institutional starting points in various parts of the world, but for the common purpose of stimulating knowledge-based economic development.

This is a different model of the relationship among the institutional spheres either than one in which the spheres are separate from each other and do not collaborate or one in which one sphere dominates the others. In figure 3, for example, depicts a model in which the state incorporates agriculture and the university.

The model of overlapping spheres is also different from the model of institutional spheres as separate from each other, which, at least in theory is how the US is supposed to work (figure 4).

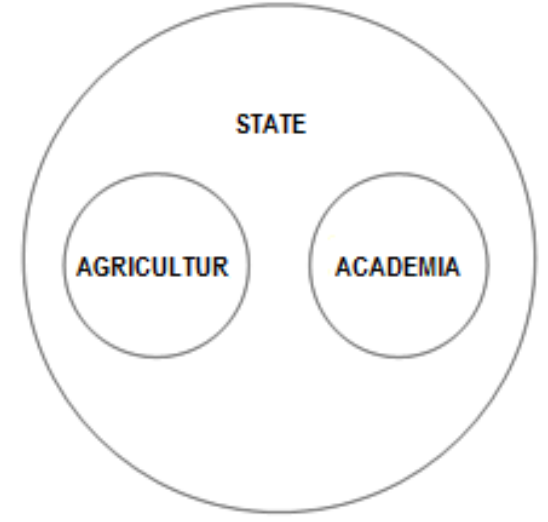

Figure 3.Relationship model

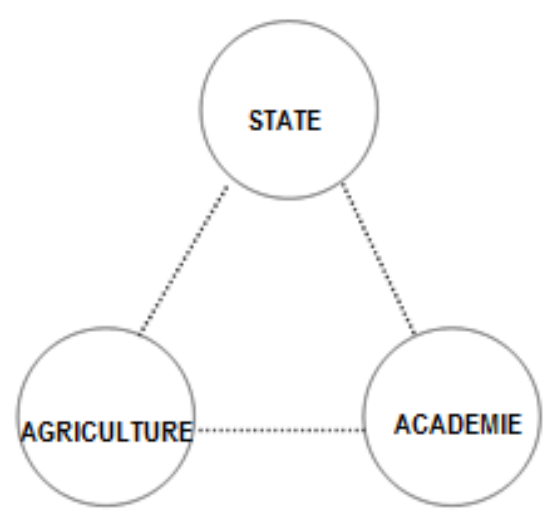

Figure 4.Relationship model.

From each of these previous models, whether it was the state dominating the other institutional spheres or the spheres separate from each other, we are moving to a model where the institutional spheres overlap and collaborate and cooperate with each other (figure 5).

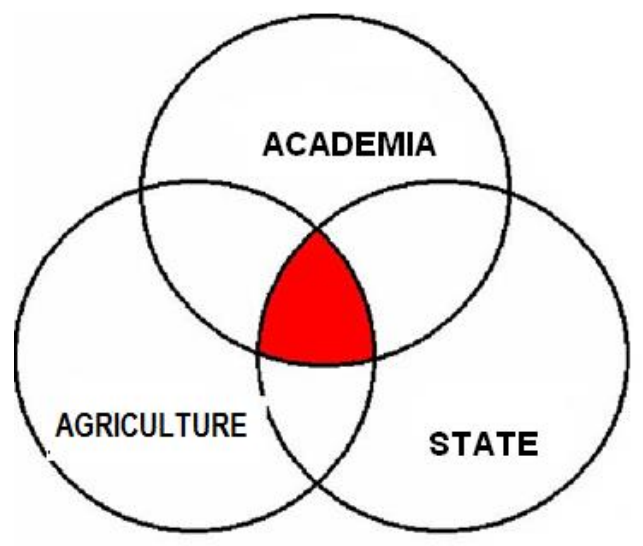

Figure 5.Relationship model

The model integrates the three "institutional spheres: research, agriculture and state. The first category is composed of researchers involved in the application of new concepts, designs and tools that they develop and universities which create educational programs focused on new vocational skills for future graduates. The second category consists of decisional factors in agriculture (entrepreneurs, investors, managers, executives). The third category consists of decisional factors in legislative and 
executive institutions of the state, which legally regulates the conditions for the functioning of agriculture, research centers and universities, public funds allocated to R \& D and education[5].

The triple helix model of innovation, with converging institutional spheres of academia, agriculture and government each taking the role of the other has been read in different ways in various parts of the world. In countries where the interface is well underway, whether occurring from the bottom up, through the interactions of individuals and organizations from different institutional spheres, or top down, encouraged by policy measures, the triple helix can be recognized as an empirical phenomenon.

There were three main forms of triple helix model. In the model "triple helix I", three spheres (university, agriculture and government) are institutionally defined. Interactions realized across the borders spheres are mediated by organizations as the agriculture liaison offices, centers of technology transfer and contract offices. In "Triple II helix ", the helix are defined as different communications systems, consisting by markets operation, technological innovation and control on the interfaces. The model "Helix Triple III" the institutional spheres (university, agriculture, government) assume each others roles, universities taking a quasi-governmental role as organizer of regional or local innovation. Triple helix model has been criticized as abstract [6].

\section{Conclusion}

In the actual situation, a solution to get out from the crisis is the state investment in researchdevelopment and stimulation of innovative work. The choosing of the appropriate model innovation can lead to the stimulation of creativity and development of innovative products and services in the economy.

A trilateral series of relationships among industries, governments and universities is emerging in regions at different stages of development and with different inherited socio-economic systems and cultural values. As regions seek to create a self-reinforcing dynamic of knowledge-based economic development, the three institutional spheres are each undergoing an internal transformation, even as new relationships are established across institutional boundaries, creating hybrid organizations such as technology centers and virtual incubators. The triple helix model and the implication of universities in innovative activity can be a solution for getting out of crisis.

In the actual situation, a solution to get out from the crisis is the state investment in researchdevelopment and stimulation of innovative work. The choosing of the appropriate model innovation can lead to the stimulation of creativity and development of innovative products and services in the economy. The triple helix model and the implication of universities in innovative activity can be a solution for getting out of crisis.

\section{References}

[1]. Schumpeter, JA 1934 The Theory of Economic Development, Cambridge, Mass.: Harvard University Press

[2]. Kline, S.J. and Rosenberg, N. 1986. "An Overview of Innovation. In: The Positive Sum Strategy: Harnessing Technology for Economic Growth. National Academy of Sciences. Washington, D.C.. http://www.nap.edu/catalog/612.html

[3]. Etzkowitz, H. 2002. The Triple Helix of University-Industry-Government Implications for Policy and Evaluation. Working Paper 2002-11, ISSN 1650-3821. http://www.sister.nu/pdf/wp_11.pdf.

[4]. Miron, D. 2008, Linking the Double Helix of Learning and to work the triple helix of universityindustry-government in the Europe of knowledge. Management \& Marketing, 3 (4), pp.3-20

[5]. Ghimisi S.,. 2015. The considerations on innovation models. Annals of Constantin Brancusi'University of Targu-Jiu. Engineering Series, (3).

[6]. Ghimisi, S., \& Nicula, D. 2019. Study to increase the quality of the scientific research process. In IOP Conference Series: Materials Science and Engineering (Vol. 564, No. 1, p. 012084). IOP Publishing. 